\title{
Towards the Understanding of Damage Mechanism of Cemented Tailings Backfill
}

\author{
Haijun Wang $\mathbb{D}^{1,2}$ \\ ${ }^{1}$ BGRIMM Technology Group, Beijing 100160, China \\ ${ }^{2}$ School of Resource and Civil Engineering, Northeastern University, Shenyang 110819, China \\ Correspondence should be addressed to Haijun Wang; 2957577750@qq.com
}

Received 9 July 2021; Accepted 31 August 2021; Published 17 September 2021

Academic Editor: Erol Yilmaz

Copyright (c) 2021 Haijun Wang. This is an open access article distributed under the Creative Commons Attribution License, which permits unrestricted use, distribution, and reproduction in any medium, provided the original work is properly cited.

Recent studies have shown that the damage characteristics of cemented tailings backfill (CTB) are influenced significantly by the variation of cement-tailings ratio, while the effects of other influencing factors remain unanswered. The CTB damage constitutive model, which takes the corrected coefficient of damage variable into consideration, and peak toughness are introduced to investigate the effects of fine tailings contents, curing ages, curing temperatures, and water-to-cement ratios $(w / c)$ on the damage evolution laws, damage $\left(D_{P}\right)$, and specific energy $\left(G_{P}\right)$ at peak stress point of CTB. The results show that appropriate content of fine tailings could improve the compressive strength of CTB and reduce its damage evolution speed and $D_{P}$. The damage growth rate of CTB decreases with curing age in early curing period and increases with higher curing temperature and $w / c . D_{P}$ of CTB takes on a descending trend with higher $w / c$ and fine tailings content but shows an increase with curing age. There exists no significant relationship between $D_{P}$ and curing temperature. $G_{P}$ of CTB increases with curing age and higher curing temperature with a quadratic function but is on a decline with increases of fine tailings content and $w / c$ with logarithmic and exponential function, respectively. The results obtained from our study have important application to the successful design of backfill structures in underground mines.

\section{Introduction}

The backfill mining method has been increasingly used in underground goaf treatment in mines worldwide, as it can effectively reduce the accumulation of surface waste and alleviate the pressure of mining operations on the surrounding environment [1-4]. From the perspective of engineering application, this mining method can effectively control the mining site pressure, reduce ore loss and dilution, and ensure the safety of underground personnel and equipment [5-10]. Cemented tailings backfill (CTB) is an essential part of the backfilling method, mainly made of tailings, cementitious materials (such as cement, fly ash, and blast furnace slag), and water in a particular proportion $[11,12]$. Its mechanical properties are influenced by internal factors, e.g., the physical and chemical properties of tailings, water-cement $(w / c)$ ratio, content and type of cementitious materials, and external factors such as curing environment (e.g., temperature and temperature humidity) and curing age $[13,14]$. As a multiphase composite medium, CTB contains initial defects such as pores, microcracks, and bubbles, resulting in the initial damage characteristics [15]. Overall, the CTB has unique failure characteristics. The stress-strain curve is unique in reflecting the failure characteristics of materials, which is commonly used to describe the damage and failure process of СТВ [16].

In recent years, many scholars have conducted in-depth studies on the damage constitutive model and damage characteristics of CTB. For example, Shulin and Yufa [17] analysed the CTB's failure mechanism with a cement-tailings $(c / t)$ ratio of $1: 6$ from the mesoscale level using solid mechanics. The damage constitutive equation of CTB under uniaxial compression was given based on the test results. Deng et al. [18] conducted uniaxial compression and split tensile tests on CTB sampled from underground backfill stopes and established the damage constitutive models using 
elastic damage theory. Liu et al. [19-21], Guicheng et al. [15], and Qiu et al. [22] established the prepeak and postpeak damage constitutive equations of CTB under uniaxial compression tests based on the strain equivalence principle, and their results had been used to guide the design in practice. Xie et al. [23] defined a damage variable based on the cumulative energy of acoustic emission and established a damage constitutive model for the CTB with a $c / t$ ratio of 1 : 8. Gong et al. [24] noticed that under the uniaxial cyclic loading and unloading conditions, the $b$ value of acoustic emission of CTB with a $c / t$ ratio of $1: 4$ showed different characteristics, indicating the dynamic evolution of the microfracture inside CTB. Zhang et al. [25] derived the damage constitutive model of cemented waste rock backfill and studied the effect of waste rock content on their damage characteristics. Yu et al. [26] proposed that the CTB stress would transfer when the damage occurs. Accordingly, they established the damage constitutive models of CTB with different $c / t$ ratios containing damage correction factors. Wang et al. [16] established the temperature-time coupled damage constitutive model of CTB based on the stress-strain curves under different initial temperatures and curing ages. Ke et al. [27] noted that the cubic polynomial function matched well with stress-strain curves of CTB with various $c$ l $t$ ratios.

To sum up, those studies have shed light on the damage evolution and characteristics of CTB. However, they mainly concentrated on the influence of the $c / t$ ratio, and the effects of other factors, e.g., $w / c$ ratio, curing age, and fine tailings content, on the damage characteristics of CTB are rarely reported. Thus, this study introduces a modified damage constitutive model to characterize the uniaxial compression stress-strain curves of CTB with various curing ages, curing temperatures, fine tailings contents, and $c / t$ ratios based on reported data and then analyse these factors' effects on the damage evolution behaviour. The peak toughness concept was also introduced to compare the damage value and specific energy at peak stress point. Our thorough study benefits to the enhanced understanding on the CTB's damage mechanism and the successful design of backfilling technique in practice.

\section{Damage Constitutive Models for Cemented Tailings Backfill}

It has been well recognized that the CTB contains random distribution of microcracks before failure and belongs to a kind of heterogeneous continuous medium. When the CTB is subjected to an external load, these defects will further expand and form macrocracks after reaching failure through a complex damage mechanism. The damage mechanic principle is suitable for describing this kind of damage mechanism, and thus it is widely used in concrete $[28,29]$, rock [30,31], and cemented backfill materials [21], such as the Weibull and Mazars damage models. In the Weibull damage model, both CTB strength and damage variable follow the Weibull distribution function, and the damage constitutive model under uniaxial compression is given as

$$
\begin{aligned}
& \sigma=E \varepsilon\left\{\exp \left[-\frac{1}{m}\left(\frac{\varepsilon}{\varepsilon_{p}}\right)^{m}\right]\right\}, \\
& D=1-\exp \left[-\frac{1}{m}\left(\frac{\varepsilon}{\varepsilon_{p}}\right)^{m}\right], \\
& m=\frac{1}{\ln \left(E \varepsilon_{p} / \sigma_{P}\right)},
\end{aligned}
$$

where $\sigma$ is the stress; $E$ is Young's modulus; $\varepsilon$ is the strain; $\varepsilon_{p}$ is the strain at peak stress point; $m$ is the shape parameter of the Weibull function; $D$ is the damage variable; and $\sigma_{P}$ is the peak stress. The Mazars model assumes that the CTB behaves almost linearly at prepeak stage and performs like the evolution behaviour of concrete at postpeak stage [20]. Before peak stress, the Mazars model for CTB is written as

$$
\begin{aligned}
\sigma & =E \varepsilon-E A \varepsilon^{\beta+1}, \\
D & =A \varepsilon^{\beta},
\end{aligned}
$$

where $A$ and $\beta$ are two constants, in which $\beta=\sigma_{p} /\left(E \varepsilon_{p}-\right.$ $\left.\sigma_{p}\right)$ and $A=1 /\left(\varepsilon_{p}^{\beta}+\beta \varepsilon_{p}^{\beta}\right)$. At postpeak stage, the stress and damage evolution model of CTB in the Mazars model is given as

$$
\begin{aligned}
\sigma & =-E D_{p} \varepsilon+E \varepsilon \exp \left[-B\left(\varepsilon-\varepsilon_{p}\right)\right], \\
D & =D_{p}+1-\exp \left[-B\left(\varepsilon-\varepsilon_{p}\right)\right] .
\end{aligned}
$$

Note that the Weibull and Mazars models do not consider the influence of residual strength, which may not efficient enough to reflect the postpeak behaviour of CTB. Therefore, a correction factor $\alpha$ was incorporated into the Weibull model (referred to as modified Weibull model for short). $\alpha$ mainly influences the postpeak stage of CTB's stress-strain curve and has minor effect on the prepeak stage. In the modified Weibull model, the stress and damage evolutions of CTB are expressed as

$$
\begin{aligned}
& \sigma=E \varepsilon\left[\alpha \exp \left(-\left(\frac{F}{F_{0}}\right)^{m}\right)+1-\alpha\right], \\
& D=1-\exp \left[-\left(\frac{F}{F_{0}}\right)^{m}\right],
\end{aligned}
$$

where $F$ is the microcosmic element strength of CTB and $m$ and $F_{0}$ are the shape parameters of the Weibull function, which can be deduced by

$$
\begin{aligned}
F & =\left(\frac{\sin \varphi}{\left.\sqrt{9+3 \sin ^{2} \varphi}+\frac{1}{\sqrt{3}}\right) E \varepsilon_{p},}\right. \\
m & =\frac{\left(\sigma_{p} / E \varepsilon_{P}\left(\left(\sigma_{p} / E \varepsilon_{P}\right)+\alpha-1\right)\right)}{\ln \alpha-\ln \left(\left(\sigma_{p} / E \varepsilon_{P}\right)+\alpha-1\right)}, \\
F_{0} & =\frac{F}{\exp \left\{\left(\ln \left[\ln \alpha-\ln \left(\left(\sigma_{p} / E \varepsilon_{P}\right)+\alpha-1\right)\right] / m\right)\right\}},
\end{aligned}
$$


where $\phi$ is the internal friction angle of CTB.

The stress-strain curves of CTB with a $c / t$ ratio of $1: 4$ given in [20] are selected to compare the performance of these three damage constitutive models in characterizing the stress and damage evolutions of CTB, as shown in Figure 1. It can be seen from Figure 1(a) that the stress-strain curves obtained by the three damage models before the peak stress are almost the same, and the stress-strain curves of the initial deformation and elastic stage of the CTB are regarded as straight lines. As the CTB enters the yield stage, the slope of the curve gradually decreases to 0 . In the failure stage of $\mathrm{CTB}$, the stress prediction value of the Mazars damage model is closer to the test result because of the consideration of residual strain, but the failure rate is higher than the test curve. Although the stress values obtained by equations (1) and (5) are slightly larger, they are consistent with the actual values, and the damage failure rate is more consistent with the test curve. The residual strength of cemented backfill is susceptible to the damage correction coefficient $\alpha$, while the curve changes slightly in the prepeak stage. It can be seen from Figure 1(b) that the changing trend of damage value $D$ obtained according to the three different damage evolution equations is the same. Before the peak stress, the damage of CTB increases slowly with the increase of stress value. When the stress value reaches the peak stress, the damage increases rapidly, indicating the formation of macrocracks and the rapid instability of the CTB. When the $c / t$ ratio is $1: 4$, the larger the correction coefficient $\alpha$ is, the slower the damage growth before the peak of the CTB is and the more significant the damage growth after the peak is. For the modified Weibull damage model, when the damage variable correction coefficient $\alpha=1$, it is equivalent to the Weibull damage model before correction.

In summary, the three damage constitutive models can reflect the stress-strain behaviour and damage failure process of the filling body under uniaxial compression reasonably, but an effective damage correction coefficient should be selected for the modified Weibull damage model. Although the model proposed in [20] is more consistent with the experimental results, the postpeak damage rate is significantly higher than the experimental curve. The residual strain value of the filling body under uniaxial compression is not easy to determine. Therefore, in the third part of the paper, the modified Weibull damage model is selected to study the influence of different factors on the damage characteristics of the filling body. The determination method of the correction coefficient of the reasonable damage variable is shown in [26].

\section{Damage Characteristics of Cemented Tailings Backfill}

3.1. Effect of Fine Tailings Content. Fall et al. [13] conducted uniaxial compression tests on CTB with various fine tailings contents (30\%, 50\%, $70 \%$, and $80 \%)$. The axial displacement loading rate was $1 \mathrm{~mm} / \mathrm{min}$. The measured results and the fitting results obtained from the modified Weibull damage model are shown in Figure 2(a). As shown in the figure, the higher the fine tailings content, the smaller the filling body's peak strength and elastic modulus. When the fine tailings content is greater than $50 \%$, the peak strength of the filling body decreases by $46.0 \%$ and $57.6 \%$, respectively. When the fine tailings content is between $30 \%$ and $50 \%$, the peak strength increases slowly by only $4.2 \%$. The reason for this is that the porosity of the CTB decreases with the decrease of the fine tailings content, which promotes the increase of bonding strength between the tailings and the cement base $[13,32]$. It can be seen from Figure 2(a) that the results obtained by fitting with the modified damage model are consistent with the experimental data, and the fine tailings content in the cemented filling body has a significant impact on its mechanical behaviour.

Figure 2(b) shows the result of damage evolution versus strain of CTB with different fine tailings contents. As shown in the figure, the damage development trend is like an S-type growth. When the fine tailings content is greater than $50 \%$, the damage growth rate increases with fine tailings content. When the fine tailings content is $30 \%-50 \%$, the higher the fine tailings content, the slower the damage growth. Figure 2(c) presents the damage values of CTB at peak stress points corresponding to different fine tailings contents. When the fine tailings content increases from $30 \%$ to $80 \%$, the corresponding $D_{p}$ is $0.61,0.13,0.57$, and 0.51 , respectively. These calculation results show that the higher the fine tailings content is, the smaller the damage value at the peak point is. It is noteworthy that the CTB with $50 \%$ fine tailings content has the advantages of high peak strength and slow damage growth, indicating that appropriate fine tailings can improve the mechanical properties of the CTB.

The deformation and damage processes of cemented backfill relate to the energy dissipation and release [7]. Under the action of external load, CTB absorbs most of the energy and uses it in the initial deformation stage. When the input energy is greater than the specific energy of the CTB (the energy absorption value at the peak stress point), the excess energy will lead to the evolution, accumulation, and coalescence of microcracks in the CTB until macrocracks occur. The concept of peak toughness in high-performance reinforced fibre reinforced concrete (HPFRC) is introduced herein, and the area under the stress-strain curve before the peak stress point is defined as the specific energy at the peak stress point of the CTB [33]. Figure 2(d) shows that specific energy of CTB with different fine tailings contents is $4.76 \times 10^{-3} \mathrm{~J} / \mathrm{m}^{3}(30 \%)$, $2.86 \times 10^{-3} \mathrm{~J} / \mathrm{m}^{3} \quad(50 \%), \quad 2.09 \times 10^{-3} \mathrm{~J} / \mathrm{m}^{3} \quad(70 \%), \quad$ and $1.34 \times 10^{-3} \mathrm{~J} / \mathrm{m}^{3}(80 \%)$, respectively, indicating that the specific energy decreases with the increase of fine tailings content. By fitting the data in Figure 2(d), the relationship between specific energy and fine tailings content is a logarithmic function, and the fitting correlation coefficient $\mathrm{R} 2$ is about 0.99 . The relationship between the two is expressed as $Y=a \ln X+b$, where $Y$ is the specific energy, $X$ is the fine tailings content, and $a$ and $b$ are the fitting correlation coefficients.

3.2. Effect of Curing Ages. Ghirian and Fall [12] studied the deformation characteristics of CTB with different curing 

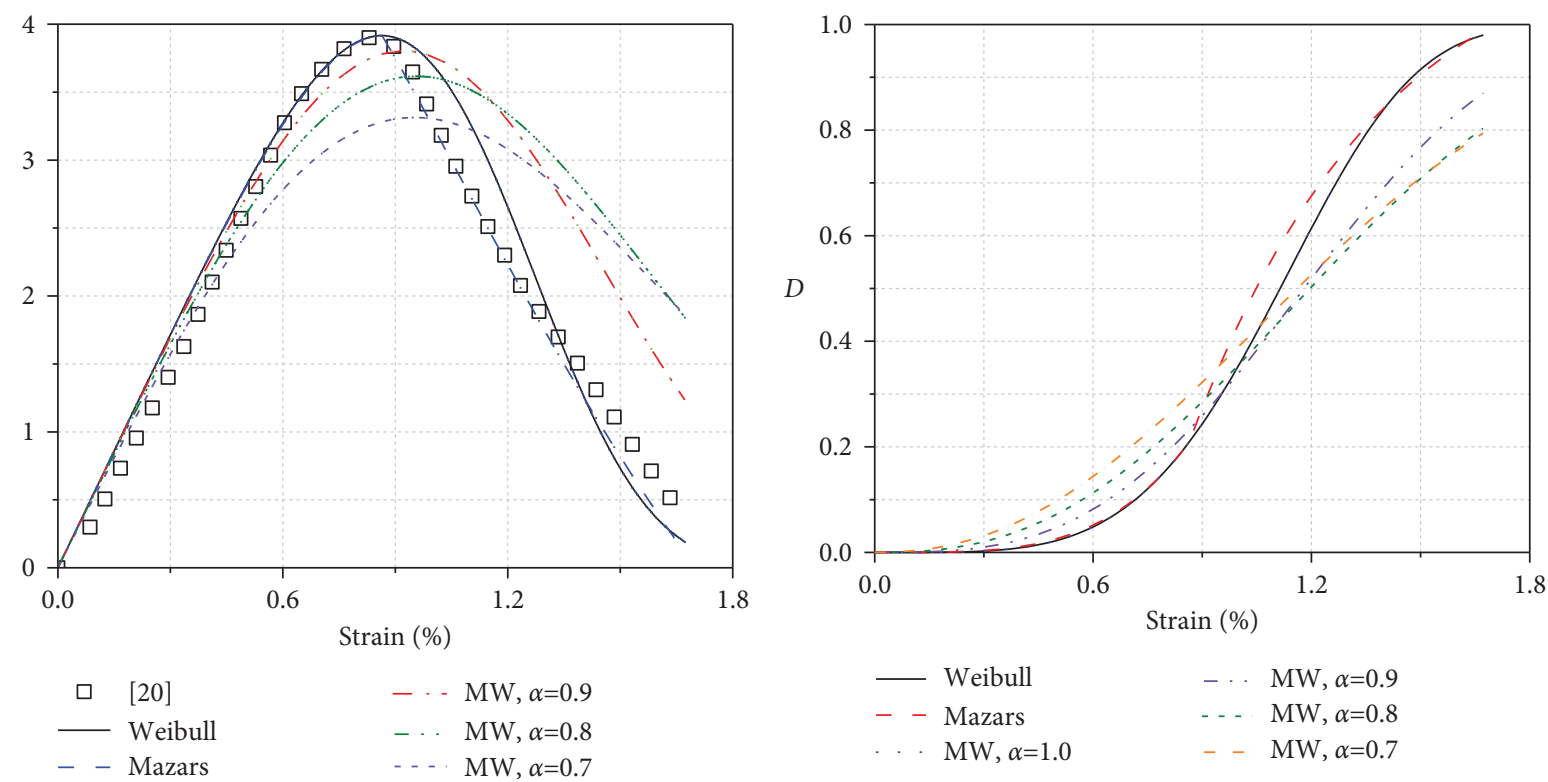
민
- - MW, $\alpha=0.9$
- ․ MW, $\alpha=0.8$
- - Mazars
MW, $\alpha=0.7$

(a)

(b)

FIgUre 1: Damage failure process of CTB with a $c / t$ ratio of $1: 4$ : (a) stress-strain curves and (b) $D$ vs. strain curves.

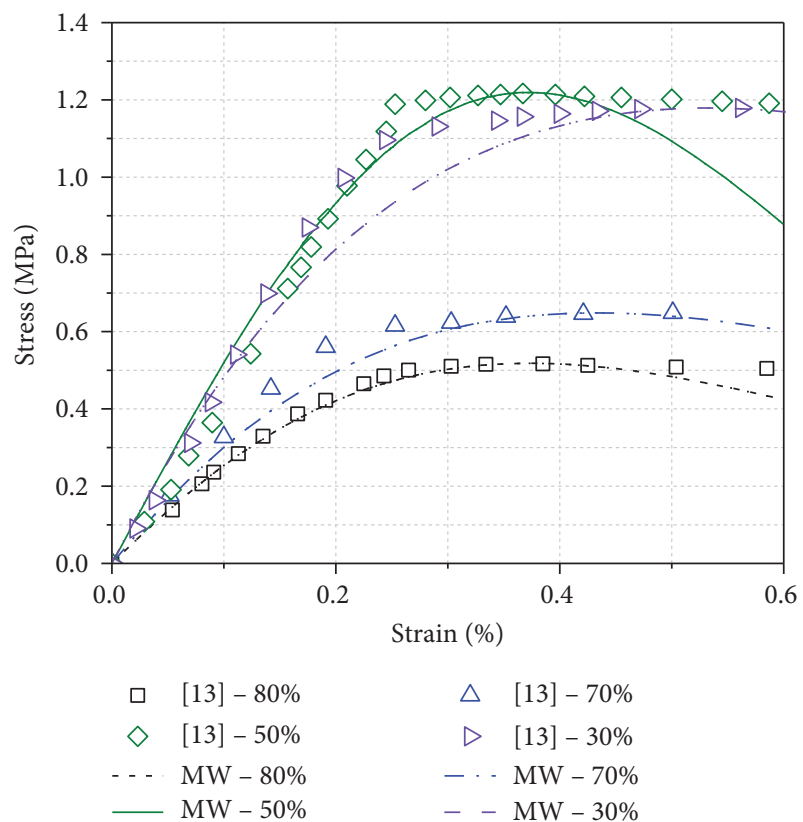

(a)

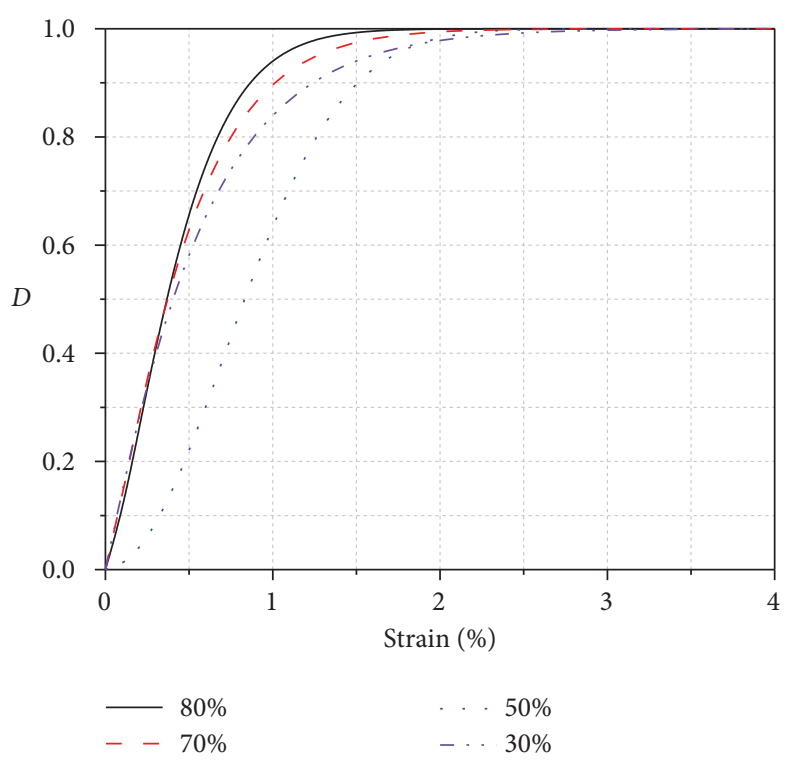

Figure 2: Continued. 


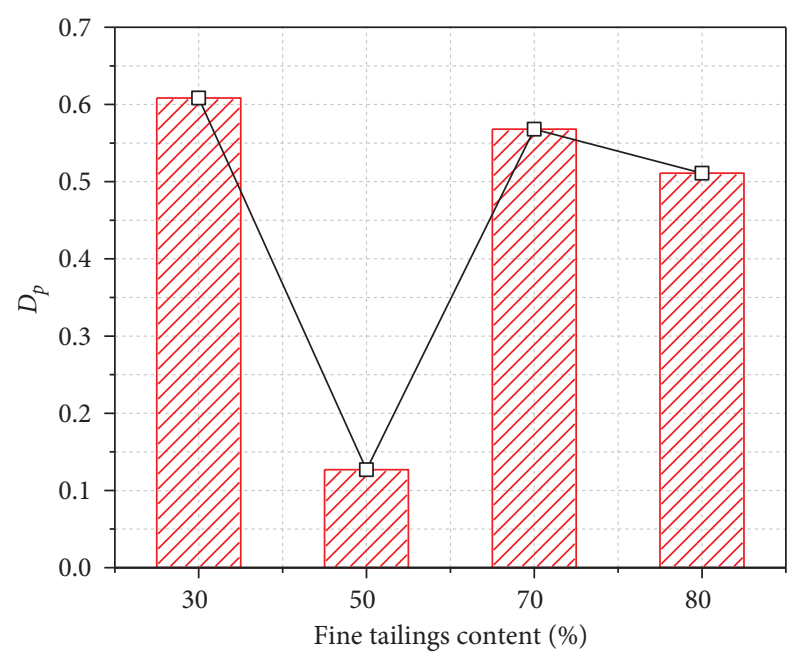

(c)

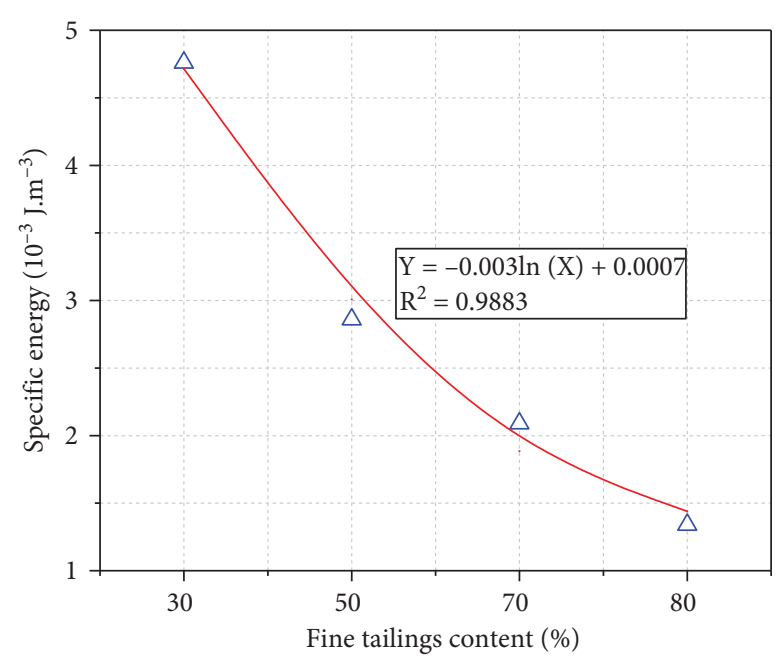

(d)

FIGURE 2: The effect of fine tailings content on damage characteristics of CTB. (a) Measured and theoretical stress-strain curves. (b) $D$ vs. strain curves. (c) $D_{P}$ vs. fine tailings content curve. (d) $G_{P}$ vs. fine tailings content curve.

ages $(7,28,90$, and 150 days) under uniaxial compression with an axial displacement loading rate of $1.14 \mathrm{~mm} / \mathrm{min}$, as shown in Figure 3(a). It can be seen from Figure 3(a) that the stress-strain behaviour of the backfill is significantly affected by curing ages, and the curves obtained from the modified Weibull damage model are in good agreement with the experimental results. Compared with the curing age of 7 days and 28 days, the long-term cured CTB can obtain higher peak strength and elastic modulus, but the peak strain decreases. The longer the curing age is, the more complete the hydration reaction inside the filling body is and the more the hydration products such as calcium silicate, C-S-H gel, and ettringite are produced, and the strength characteristics and durability of the material are further improved [34]. When the curing age is short, the CTB shows plastic deformation. With the increase of curing age, the filling body gradually shows brittle behaviour. It is because the CTB with a higher strength absorbs more energy before reaching the peak stress point and thus benefits the propagation of internal microcracks. As a result, the deformation of CTB after reaching peak stress point is more severe, together with the abrupt reduction in strength.

Figure 3(b) shows the change curve of the damage evolution of CTB with strain at different curing ages. As shown in the figure, the damage value increases with the increase of strain in an S-shaped curve. When the curing age is short (less than 28 days), the damage growth rate of CTB is inversely proportional to the curing age. Compared with the CTB with shorter curing ages, the damage evolution of CTB with longer curing ages is divided into two stages. Before the peak stress point, the damage growth is slow and the shorter the curing age is, the slower the damage growth rate is. After peak stress, the damage of CTB increases rapidly. The shorter the curing age is, the faster the damage growth rate is. Figure 3(c) shows the damage value corresponding to the peak point of the CTB at different curing ages. The 7-day cured CTB's damage value at peak stress point is about 0.35 . When the curing age increases to 28,90 , and 150 days, the corresponding $\mathrm{Dp}$ is $0.50,0.42$, and 0.51 , respectively. Overall, the damage value of CTB at peak stress point increases with the increase of curing age.

Figure 3(d) shows the curve of the peak stress ratio energy of the filling body changing with the curing age. The specific energy corresponding to different curing ages $(7,28,90$, and 150 days) is $3.98 \times 10^{-3} \mathrm{~J} / \mathrm{m}^{3}, 5.06 \times 10^{-3} \mathrm{~J} / \mathrm{m}^{3}, 5.11 \times 10^{-3} \mathrm{~J} / \mathrm{m}^{3}$, and $9.31 \times 10^{-3} \mathrm{~J} / \mathrm{m}^{3}$, respectively. It indicates that the longer the curing age is, the more the energy absorbed by the CTB when it reaches the peak stress point is and the greater the peak stress ratio energy is. The statistical regression analysis of the curve shows that the specific energy has a quadratic function relationship with the curing age, and the fitting correlation coefficient is about 0.94 . The relationship between the two is expressed as $Y=a X^{2}+b X+c$ where $Y$ is the specific energy at the peak stress point, $X$ is the curing age, and $a, b$, and $c$ are the test correlation coefficients.

3.3. Effect of Curing Temperatures. The influence of curing temperature on the uniaxial deformation characteristic of CTB was studied in [35]. The experimental results, together with theoretical curves obtained from the modified Weibull damage model, are shown in Figure 4(a). As shown in the figure, a good agreement is obtained between the experimental and predicted results. The higher the curing temperature, the greater the elastic modulus of the CTB, the higher the peak strength, and the smaller the strain at the peak stress point. When the curing temperature increased from $20^{\circ} \mathrm{C}$ to $50^{\circ} \mathrm{C}$, the peak strength increased by $81.6 \%\left(20^{\circ} \mathrm{C}\right), 133.9 \%\left(35^{\circ} \mathrm{C}\right)$, and $374.1 \%$ $\left(50^{\circ} \mathrm{C}\right)$, respectively, and the peak strain decreased by $24.8 \%, 39.7 \%$, and $69.9 \%$, respectively. The reasons why an 


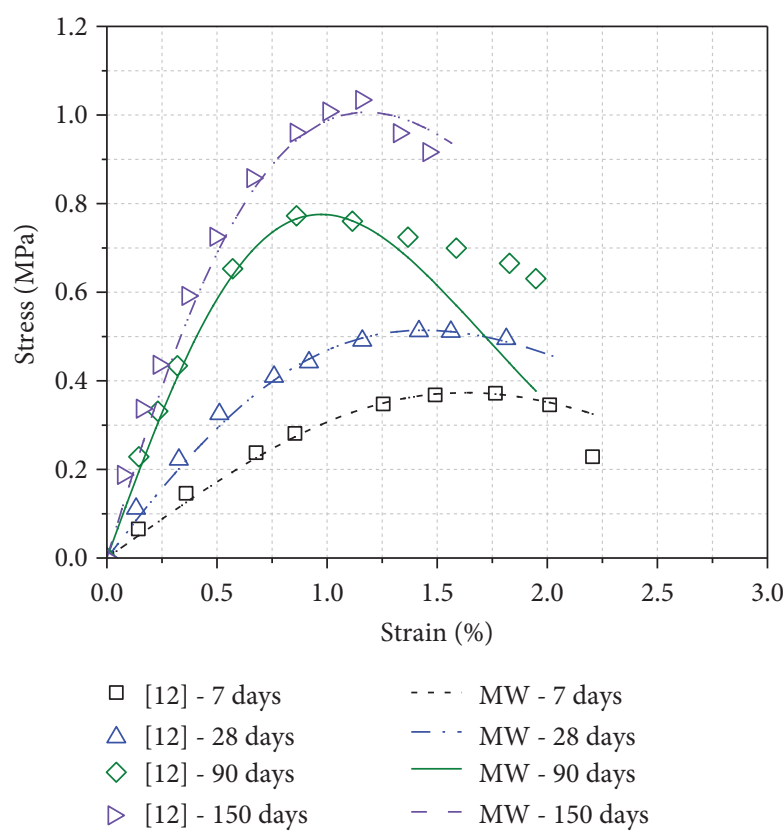

(a)

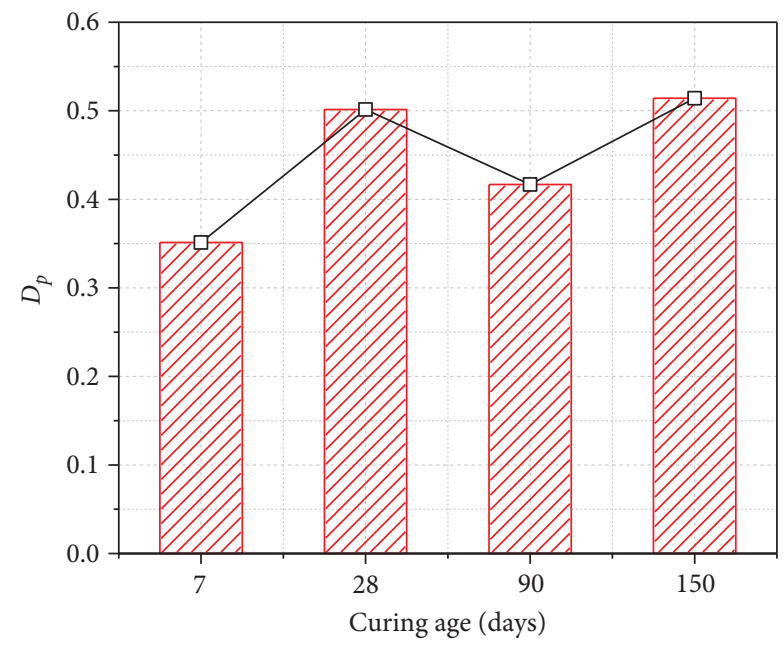

(c)

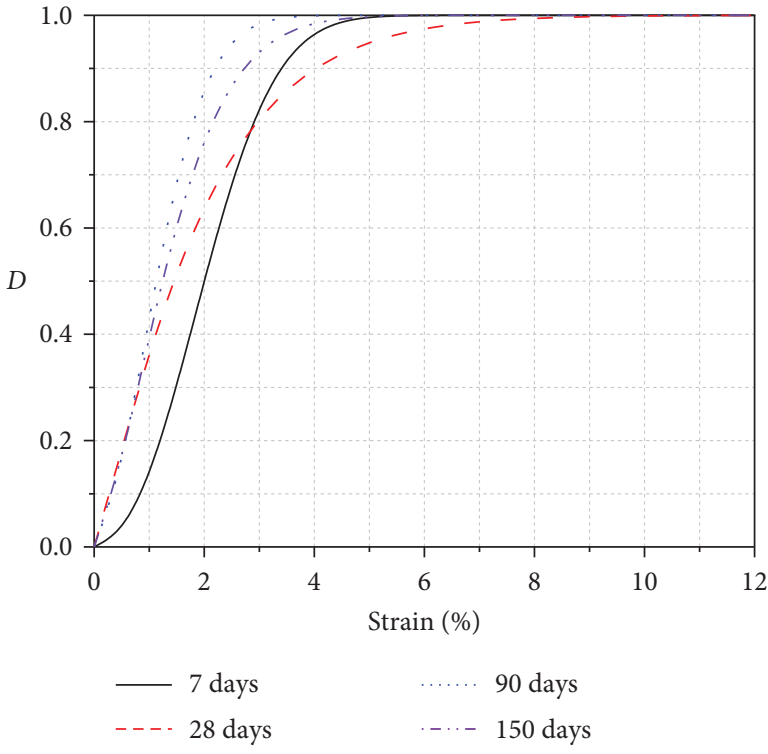

(b)

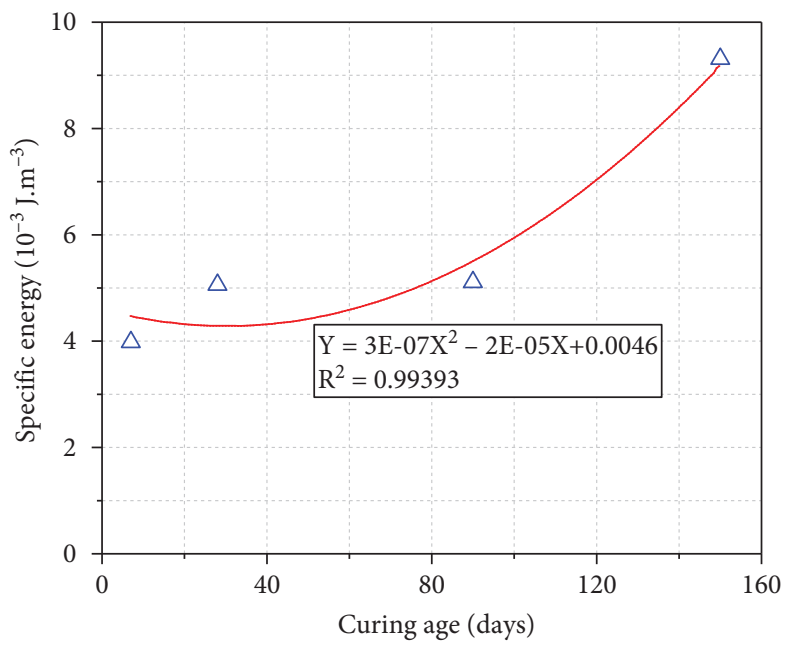

(d)

Figure 3: The effect of curing ages on damage characteristics of CTB. (a) Measured and theoretical stress-strain curves. (b) $D$ vs. strain curves. (c) $D_{P}$ vs. curing age curve. (d) $G_{P}$ vs. curing age curve.

appropriate high temperature can promote the strength growth of the CTB are mainly the following two aspects. Firstly, it promotes the cement hydration reaction in the CTB and generates more hydration products such as C-S$\mathrm{H}$ gel $[35,36]$ to improve its peak strength and stiffness and shorten its postpeak deformation period [35]. Secondly, the increase of temperature accelerates the capillary water consumption rate and promotes the development of pore water pressure in the filling body, resulting in higher strength [37].

Figure 4(b) shows the curve of damage value changing with strain under different curing temperatures. When the curing temperature is $20^{\circ} \mathrm{C}$ and $50^{\circ} \mathrm{C}$, the damage shows an S-shaped curve. The damage increases slowly before the peak point and rapidly after the peak point. When the curing temperature was $20^{\circ} \mathrm{C}$ and $35^{\circ} \mathrm{C}$, the damage evolution rate of the CTB gradually decreases with the increase of strain. Also, the damage increases rapidly before the peak stress point, while the damage increases slowly after the peak point, showing the characteristics of strain softening. Figure 4(c) shows that when the curing temperature is less than $20^{\circ} \mathrm{C}$, the damage value at the peak stress point increases with the increase of curing temperature. When the temperature is more significant than $20^{\circ} \mathrm{C}$, the peak damage value decreases with the increase of curing temperature. For the $\mathrm{CTB}$ with a curing temperature of $50^{\circ} \mathrm{C}$, the damage value increases rapidly to 1 after the peak stress point, indicating that the CTB gradually exhibits brittle characteristics with the increase of curing temperature.

Figure $4(\mathrm{~d})$ shows the peak specific energy curves of backfill at different curing temperatures. When the initial 


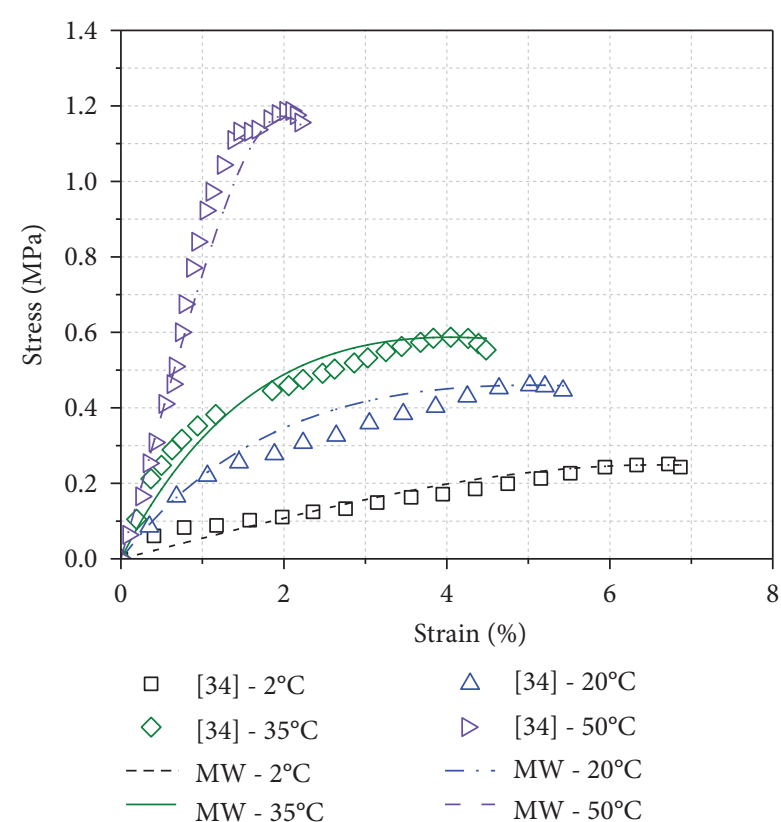

(a)

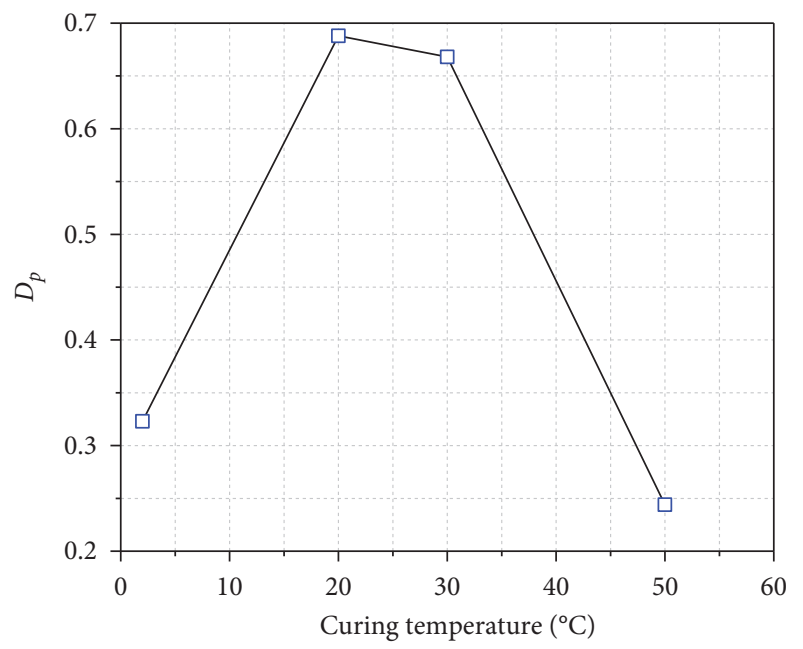

(c)

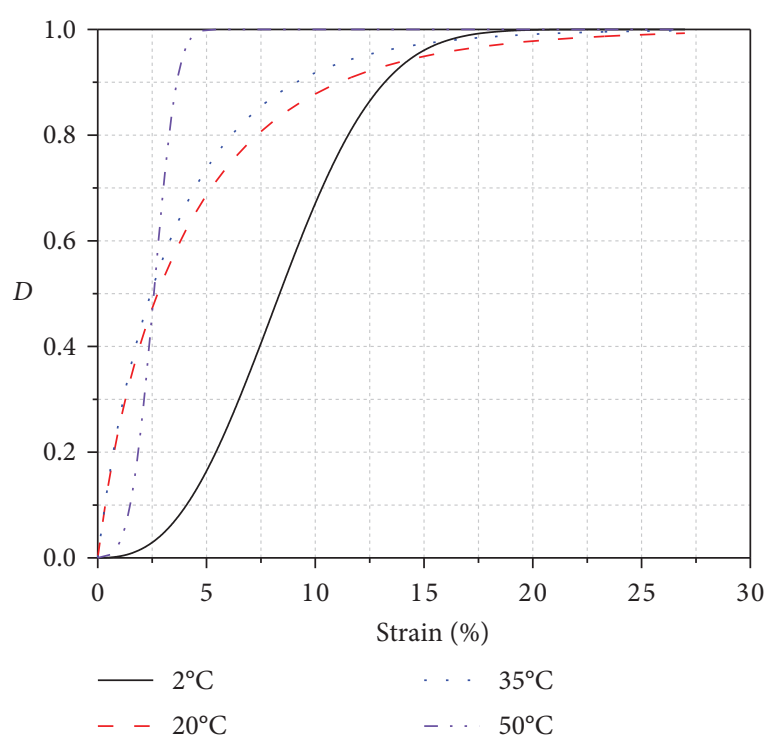

(b)

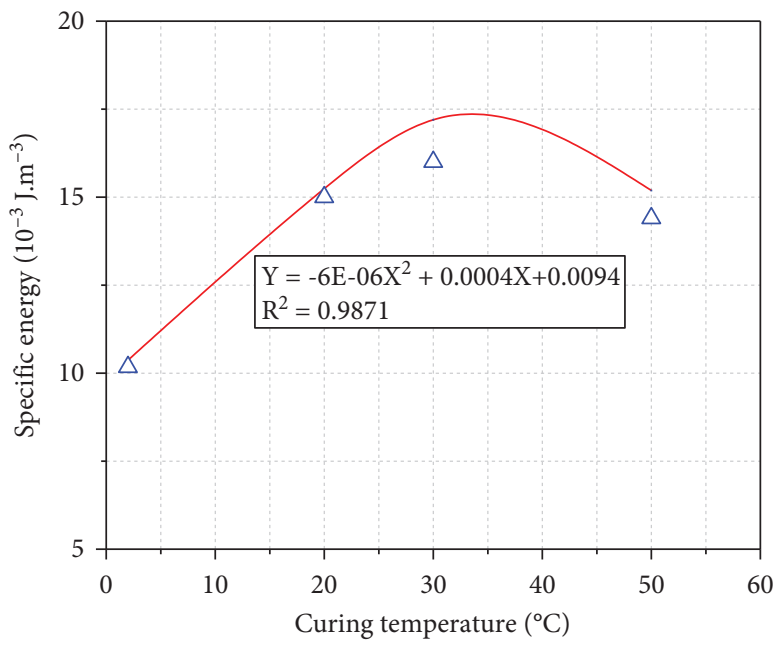

(d)

FIgURE 4: The effect of curing temperatures on damage characteristics of CTB. (a) Measured and theoretical stress-strain curves. (b) $D$ vs. strain curves. (c) $D_{P}$ vs. curing temperature curve. (d) $G_{P}$ vs. curing temperature curve.

curing temperature is $2^{\circ} \mathrm{C}$, the peak strain ratio of the backfill is $1.04 \times 10^{-3} \mathrm{~J} / \mathrm{m}^{3}$. When the curing temperature increases to $20^{\circ} \mathrm{C}, 35^{\circ} \mathrm{C}$, and $50^{\circ} \mathrm{C}$, the specific energy of the backfill is $1.47,1.66$, and 1.46 times that of $20^{\circ} \mathrm{C}$. It denotes that when the curing temperature is less than $35^{\circ} \mathrm{C}$, the specific energy increases with the increase of temperature. When the curing temperature exceeds $35^{\circ} \mathrm{C}$, the peak strain ratio energy decreases gradually. The regression analysis shows that the specific energy has a quadratic relationship with the curing temperature, and the fitting correlation coefficient $\mathrm{R} 2$ is about 0.99 . The relationship between the two is expressed as $Y=a X^{2}+b X+c$ where $Y$ is the specific energy at the peak stress point, $X$ is the curing temperature, and $a, b$, and $c$ are the correlation coefficients.
3.4. Effect of Water-Cement Ratios. The stress-strain behaviour of fillings with different $w / c$ ratios $(7,10$, and 13) under uniaxial compression was studied in [13]. The experimental results are compared with the predicted curves obtained from the modified Weibull damage model in Figure 5(a). The theoretical curves show a good agreement with the experimental results. The stress-strain curve of the CTB is significantly affected by the water-cement ratio. The peak strength, residual strength, and elastic model of the CTB increase with the decrease of the water-cement ratio. The decrease of the water-cement ratio will increase the content of columnar ettringite in the filling body and reduce the porosity in the CTB, and the porosity is inversely proportional to the material strength [38]. When the watercement ratio is 7 , the corresponding peak strength is 


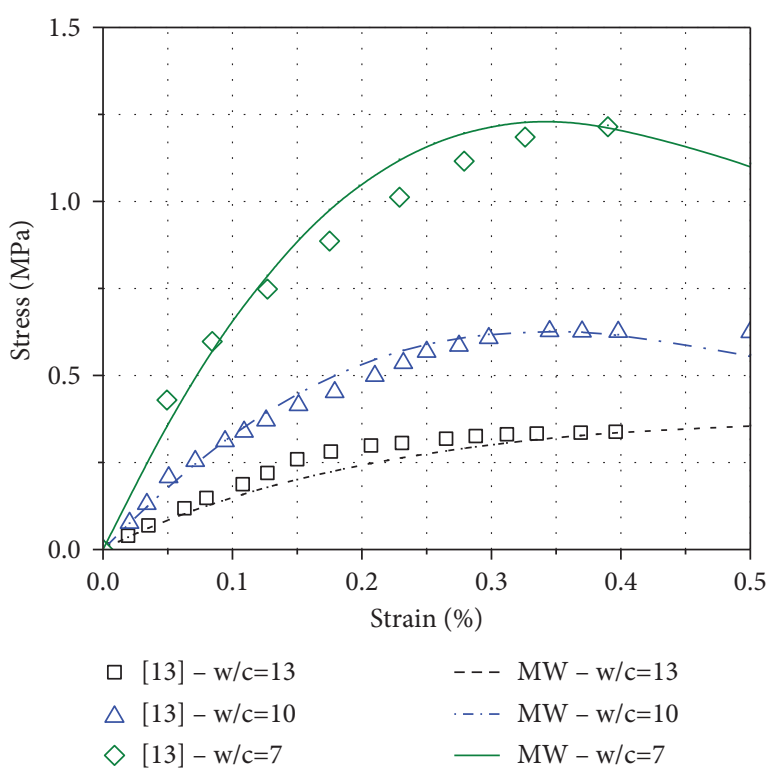

(a)

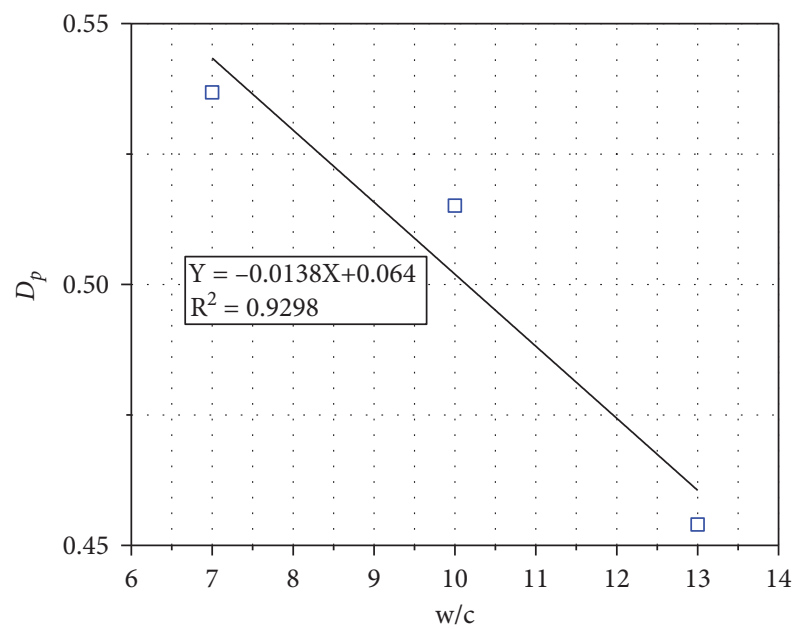

(c)

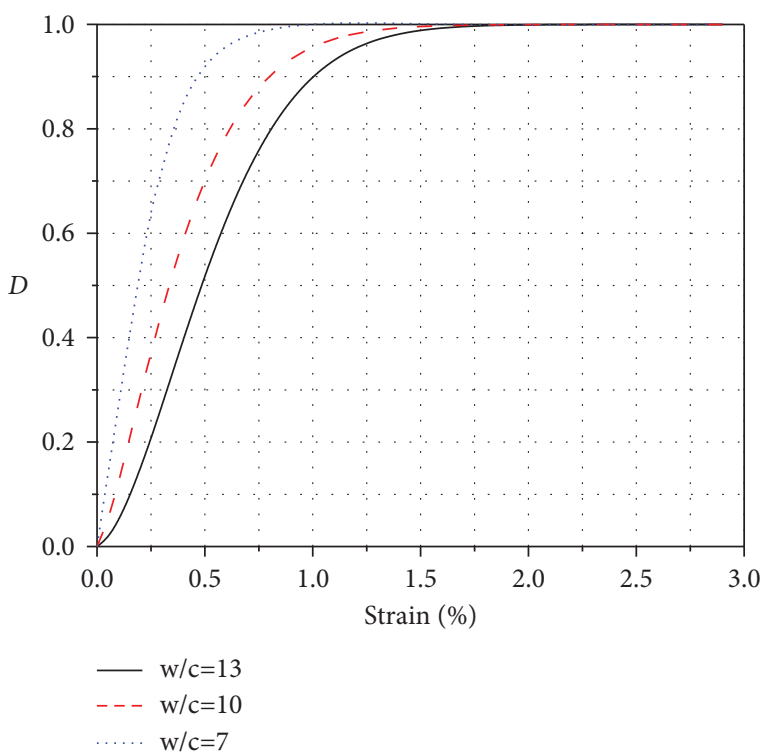

(b)

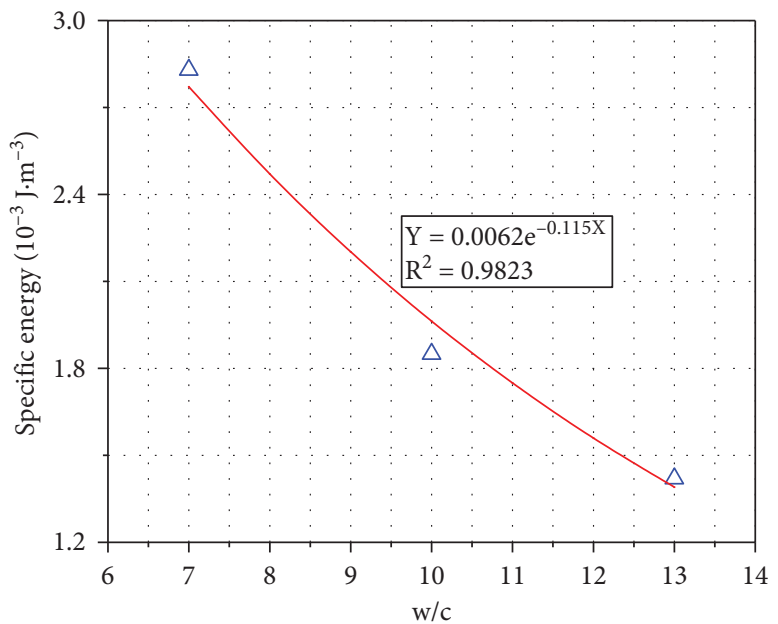

(d)

FIGURE 5: The effect of water-to-cement ratios on damage characteristics of CTB. (a) Measured and theoretical stress-strain curves. (b) $D$ vs. strain curves. (c) $D_{P}$ vs. water-to-cement curve. (d) $G_{P}$ vs. water-cement ratio curve.

1.23 $\mathrm{MPa}$. When the water-cement ratio increases to 10 and 13 , the peak strength of the CTB decreases to $0.63 \mathrm{MPa}$ and $0.37 \mathrm{MPa}$, respectively.

Figure 5(b) shows the curve of the damage value of the CTB with different water-cement ratios. The damage value of the CTB increases with the increase of strain, and the smaller the water-cement ratio, the faster the damage growth of the CTB. As shown in Figure 5(c), the damage values corresponding to the peak stress point are 0.54 , 0.52 , and 0.45 when the water-cement ratio of the CTB is 7,10 , and 13, respectively. The regression analysis of the data shows that the damage value of the peak stress point is linearly related to the water-cement ratio and decreases linearly with the increase of the water-cement ratio. The fitting correlation coefficient is about 0.93 , indicating that there is a high regularity between the two. The relationship between the two is expressed as $Y=a X+b$, where $Y$ is the damage value corresponding to the peak stress point, $X$ is the water-cement ratio, and $a$ and $b$ are the correlation coefficients.

Figure 5(d) shows the variation curve of specific energy with the water-cement ratio. The figure shows that when the initial water-cement ratio is 7 , the specific energy is determined as $2.83 \times 10^{-3} \mathrm{~J} / \mathrm{m}^{3}$. When the water-cement ratio increases to 10 and 13 , respectively, the specific energy of CTB decreases by $34.63 \%$ and $49.83 \%$. This shows that the smaller the water-cement ratio, the more the energy absorbed by the CTB when reaching the peak point, and the greater the strength. The data fitting between specific energy and water-cement ratio has an obvious exponential function, and the correlation coefficient is as high as 0.98 . The relationship between them is $Y=A e^{B X}$, where $Y$ is the specific energy of the CTB, $X$ is the water-cement ratio, and $A$ and $B$ are the test correlation coefficients. 
It is well known that the leaching risk from CPB to groundwater proposed by Chen et. al. has been an important issue in mining engineering, which will be further studied in our future research.

\section{Conclusions}

In this study, a modified Weibull damage model is introduced to characterize the damage mechanism of cemented tailings backfill with various curing ages, curing temperatures, water-cement ratios, and fine tailings contents. Based on the results, the following conclusions can be drawn:

(1) As a kind of multiphase composite material containing initial defects such as microcracks and pores, CTB's mechanical properties and damage characteristics are significantly affected by the fine tailings content, curing age, curing temperature, and water-cement ratio.

(2) The damage growth rate of CTB increases with fine tailings content when the fine tailings content is more than $50 \%$ but decreases when the content of fine tailings is less than $50 \%$. It indicates that appropriate content of fine tailings can effectively improve the mechanical properties of the CTB. The damage growth rate is inversely proportional to the curing age for the CTB with low curing age. For longterm curing CTB, the more significant the curing age, the faster the damage growth before the peak stress point and the slower the damage growth after the peak stress point. With the increase of curing temperature, the CTB gradually shows brittle behaviour. The higher the curing temperature, the faster the damage growth rate of the CTB and the more sudden the failure process. The greater the water-cement ratio, the faster the damage development inside CTB.

(3) The damage value at the peak stress point of the CTB decreases with the increase of fine tailings content (except 50\%), decreases with the increase of watercement ratio, and increases gradually with the increase of curing age but does not show apparent regularity with the curing temperature.

(4) The specific energy is the energy absorbed at the peak stress point, proportional to the uniaxial compressive strength of CTB. The specific energy grows in a quadratic polynomial manner with the increase of curing age and curing temperature, decreases logarithmically with fine tailings content, and follows the exponential reduction law with increasing watercement ratio.

\section{Data Availability}

The data used to support the findings of this study are included within the article.

\section{Conflicts of Interest}

The author declares that there are no conflicts of interest.

\section{Acknowledgments}

This study was financially supported by the Study on Identification of Key Characteristic Variables for Stability of Chamber Group in Underground Concentrator (02-1922).

\section{References}

[1] M. Benzaazoua, M. Fall, and T. Belem, "A contribution to understanding the hardening process of cemented pastefill," Minerals Engineering, vol. 17, no. 2, pp. 141-152, 2004.

[2] A. Ghirian and M. Fall, "Coupled thermo-hydro-mechanicalchemical behaviour of cemented paste backfill in column experiments. part I: physical, hydraulic and thermal processes and characteristics," Engineering Geology, vol. 164, pp. 195207, 2013.

[3] L. Li, "Generalized solution for mining backfill design," International Journal of Geomechanics, vol. 14, no. 3, Article ID 04014006, 2014.

[4] Z. Guo, J. Qiu, H. Jiang, S. Zhang, and H. Ding, "Improving the performance of superfine-tailings cemented paste backfill with a new blended binder," Powder Technology, vol. 394, 2021.

[5] F. Cihangir, B. Ercikdi, A. Kesimal, A. Turan, and H. Deveci, "Utilisation of alkali-activated blast furnace slag in paste backfill of high-sulphide mill tailings: effect of binder type and dosage," Minerals Engineering, vol. 30, pp. 33-43, 2012.

[6] Z. Guo, J. Qiu, H. Jiang, J. Xing, X. Sun, and Z. Ma, "Flowability of ultrafine-tailings cemented paste backfill incorporating superplasticizer: insight from water film thickness theory," Powder Technology, vol. 381, pp. 509-517, 2021.

[7] J. Qiu, L. Yang, X. Sun, J. Xing, and S. Li, "Strength characteristics and failure mechanism of cemented super-fine unclassified tailings backfill," Minerals, vol. 7, no. 4, p. 58, 2017.

[8] S. Yin, A. Wu, K. Hu, Y. Wang, and Y. Zhang, "The effect of solid components on the rheological and mechanical properties of cemented paste backfill," Minerals Engineering, vol. 35, pp. 61-66, 2012.

[9] T. Belem and M. Benzaazoua, "Design and application of underground mine paste backfill technology," Geotechnical \& Geological Engineering, vol. 26, no. 2, pp. 147-174, 2008.

[10] M. Fall, M. Benzaazoua, and S. Ouellet, "Experimental characterization of the influence of tailings fineness and density on the quality of cemented paste backfill," Minerals Engineering, vol. 18, no. 1, pp. 41-44, 2005.

[11] B. Ercikdi, G. Külekci, and T. Yılmaz, "Utilization of granulated marble wastes and waste bricks as mineral admixture in cemented paste backfill of sulphide-rich tailings," Construction and Building Materials, vol. 93, pp. 573-583, 2015.

[12] A. Ghirian and M. Fall, "Coupled thermo-hydro-mechanicalchemical behaviour of cemented paste backfill in column experiments," Engineering Geology, vol. 170, pp. 11-23, 2014.

[13] M. Fall, T. Belem, S. Samb, and M. Benzaazoua, "Experimental characterization of the stress-strain behaviour of cemented paste backfill in compression," Journal of Materials Science, vol. 42, no. 11, pp. 3914-3922, 2007.

[14] J. Qiu, Z. Guo, L. Yang, H. Jiang, and Y. Zhao, "Effects of packing density and water film thickness on the fluidity behaviour of cemented paste backfill," Powder Technology, vol. 359, pp. 27-35, 2020.

[15] H. Guicheng, L. Shenglong, and H. Bingxiang, "Reasonable matching for cemented waste rock backfill and sand shale," 
Journal of Mining \& Safety Engineering, vol. 34, no. 2, pp. 371-377, 2017.

[16] Y. Wang, A. Wu, H. Wang et al., "Damage constitutive model of cemented tailing paste under initial temperature effect," Chinese Journal of Engineering, vol. 39, no. 1, pp. 31-38, 2017.

[17] L. Shulin and S. Yufa, "The fracture mechanism and damage constitutive equation of cemented tail filling," Gold, vol. 18, pp. 24-29, 1997.

[18] D. Deng, Y. Yang, and Z. Yao, "Research on constitutive equation of damage evolution of backfill based on the full tensile and compressive process," Journal of Mining \& Safety Engineering, vol. 4, pp. 485-488, 2006.

[19] Z. Liu, X. Li, G. Zhao, Q. Li, and W. Wang, "Three-dimensional energy dissipation laws and reasonable matches between backfill and rock mass," Chinese Journal of Rock Mechanics and Engineering, vol. 29, no. 2, pp. 344-348, 2010.

[20] Z.-x. Liu, X.-B. Li, T.-g. Dai, and P. Cao, "On damage model of cemented tailings backfill and its match with rock mass," Yan Tu Li Xue, vol. 27, no. 9, pp. 1442-1446, 2006.

[21] Z.-x. Liu, M. Lan, S.-y. Xiao, and H.-q. Guo, "Damage failure of cemented backfill and its reasonable match with rock mass," Transactions of Nonferrous Metals Society of China, vol. 25, no. 3, pp. 954-959, 2015.

[22] J.-P. Qiu, L. Yang, J. Xing, and X.-G. Sun, “Analytical solution for determining the required strength of mine backfill based on its damage constitutive model," Soil Mechanics and Foundation Engineering, vol. 54, no. 6, 2018.

[23] Y. Xie, W. He, Z. Zhu, X. Liu, H. Liu, and T. Xie, "Study on backfill acoustic emission characteristic and damage evolution under uniaxial compression," Chinese Journal of Applied Mechanics, vol. 32, no. 4, pp. 670-676, 2015.

[24] C. Gong, C. Li, and K. Zhao, "Experimental study on b-value characteristics of acoustic emission of cemented filling body under loading and unloading test," Journal of Mining and Safety Engineering, vol. 31, no. 5, pp. 788-794, 2014.

[25] F. Zhang, W. Liu, and L. Shen, "Damage constitutive model for cemented paste backfill after mixing waste rock," in Proceedings of the World Automation Congress 2012, pp. 1-4, IEEE, Puerto Vallarta, Mexico, 24-28 June 2012.

[26] G. B. Yu, P. Yang, and Y. Z. Chen, "Study on damage constitutive model of cemented tailings backfill under uniaxial compression," in Applied Mechanics and Materialsvol. 353-356, pp. 379-383, Trans Tech Publ, 2013.

[27] Y.-x. Ke, X.-m. Wang, Q.-l. Zhang, and E.-y. Liu, "Strength determination of crude tailings backfill in deep mine based on non-linear constitutive model," Journal of Northeastern University, vol. 38, no. 2, p. 280, 2017.

[28] B. S. Underwood, "A continuum damage model for asphalt cement and asphalt mastic fatigue," International Journal of Fatigue, vol. 82, pp. 387-401, 2016.

[29] J. Zhou and X. Chen, "Stress-strain behavior and statistical continuous damage model of cement mortar under high strain rates," Journal of Materials in Civil Engineering, vol. 25, no. 1, pp. 120-130, 2013.

[30] R. Cao, S. He, J. Wei, and F. Wang, "Study of modified statistical damage softening constitutive model for rock considering residual strength," Rock and Soil Mechanics, vol. 34, no. 6, pp. 1652-1660, 2013.

[31] H. Zhao, C. Shi, M. Zhao, and X. Li, "Statistical damage constitutive model for rocks considering residual strength," International Journal of Geomechanics, vol. 17, no. 1, Article ID 04016033, 2017.

[32] X. Ke, X. Zhou, X. Wang, T. Wang, H. Hou, and M. Zhou, "Effect of tailings fineness on the pore structure development of cemented paste backfill," Construction and Building Materials, vol. 126, pp. 345-350, 2016.

[33] D.-Y. Yoo, S. Kim, G.-J. Park, J.-J. Park, and S.-W. Kim, "Effects of fiber shape, aspect ratio, and volume fraction on flexural behavior of ultra-high-performance fiber-reinforced cement composites," Composite Structures, vol. 174, pp. 375-388, 2017.

[34] S. Zhang, L. Yang, F. Ren, J. Qiu, and H. Ding, "Rheological and mechanical properties of cemented foam backfill: effect of mineral admixture type and dosage," Cement and Concrete Composites, vol. 112, Article ID 103689, 2020.

[35] M. Fall, J. Célestin, M. Pokharel, and M. Touré, "A contribution to understanding the effects of curing temperature on the mechanical properties of mine cemented tailings backfill," Engineering Geology, vol. 114, no. 3-4, pp. 397-413, 2010.

[36] D. Wu, G. Sun, and G. Huang, "Experimental and simulation study on seepage characteristics of cemented tailings backfill," Journal of Central South University, vol. 46, no. 3, pp. 10501057, 2015.

[37] N. Abdul-Hussain and M. Fall, "Thermo-hydro-mechanical behaviour of sodium silicate-cemented paste tailings in column experiments," Tunnelling and Underground Space Technology, vol. 29, pp. 85-93, 2012.

[38] M. Fall, M. Benzaazoua, and E. G. Saa, "Mix proportioning of underground cemented tailings backfill," Tunnelling and Underground Space Technology, vol. 23, no. 1, pp. 80-90, 2008. 